\title{
Hyperbaton în Prodigiorum liber al lui Obsequens
}

\author{
Claudia Tărnăuceanu ${ }^{\mathbb{A} \mathbb{R}^{\circledR} \star}$ \\ Facultatea de Litere, Universitatea „Alexandru Ioan Cuza”, Bd. Carol I 11, 700506 Iași, România
}

\begin{abstract}
Despre articol
Istoric:

Primit 1 aprilie 2021

Acceptat 23 aprilie 2021

Publicat 18 august 2021

Cuvinte-cheie:

stilistică

analiză de text

Rezumat

Opusculul cunoscut sub titlul Prodigiorum liber, un inventar al fenomenelor ieșite din comun despre care se credea că prevestesc evenimente importante, redactat la sfirșitul secolului al IV-lea de Obsequens, poate fi încadrat în categoria textelor de „specialitate”, cu un limbaj aparte (sermoprodigialis) și un stil specific. Dat fiind caracterul "tehnic" al unei astfel de scrieri, unde accentul este pus pe concizie și claritate, este de așteptat ca ocurența unor figuri topice precum byperbaton-ul să nu fie foarte frecventă. Scopul acestui studiu este analiza modului de realizare și a rolului acestei figuri în Prodigiorum liber. În urma examinării, se observă că hyperbaton-ul, prezent într-un număr suficient de mare de exemple, apare preponderent ca mijloc pragmatic de punere în relief, utilizarea sa ca ornament stilistic, cu diverse valențe expresive, fiind foarte restrînsă.
\end{abstract}

\section{Introducere}

Autor despre care se cunosc puține date, Iulius Obsequens a redactat la sfirșitul secolului al IV-lea ${ }^{1}$ un opuscul conținînd inventarul prodigiilor care au anunţat evenimente importante din anul 564 A.U.C. (190 a.C.) pînă în 743 A.U.C. (11 a.C.). Cunoscută sub denumirea de Prodigiorum liber sau Deprodigiis liber $^{2}$, lucrarea, fără pretenții literare, inventariind fenomene ieșite din comun, prevestiri ale unor evenimente speciale, petrecute cu patru secole mai înainte, pare a se adresa unui public eterogen, format atît din intelectuali interesați de curiozități, din reprezentanți ai elitei politice, care recunoșteau potențialul propagandistic al interpretării semnelor divine, cît și din oameni în mentalitatea cărora era bine înrădăcinată credința în semnificațiile prodigiilor (prodigia) și în necesitatea ritualurilor expiatorii (procurationes) ${ }^{3}$. Scrierea, care are ca sursă principală textul lui Titus Livius (sau o epitomă a acestuia) ${ }^{4}$, urmează un tipar bine stabilit, rigid, apropiat de cel al analisticii ${ }^{5}$. Evenimentele sînt prezentate în ordine cronologică, anii fiind precizați în funcție de consulii eponimi. Fiecare secvență începe prin menționarea locului unde s-a petrecut faptul ieșit din comun, urmată de expunerea succintă a prevestirilor și de interpretarea acestora.

Redactat într-o latină clară şi destul de îngrijită, textul se caracterizează prin concizie și simplitate. Preferința pentru parataxă, elipsa verbului esse din formele pasive compuse, abundența participialelor, reducerea hipotaxei și limitarea la uzul anumitor subordonate, ponderea redusă a procedeelor stilistice, formulele repetitive, lexicul specific au dus la identificarea unui stil aparte al unei astfel de scrieri „tehnice”,

*Adresă de corespondență: dorinaclaudia@yahoo.com.

${ }^{1}$ V. discuția cu privire la autor și data elaborării lucrării în Trixi (ed. 2017, p. XVII-XXIII); Mastandrea (ed. 2005, p. VVII), Picone (1974).

${ }^{2}$ Prima ediție a fost publicată în 1508, la Veneția. Despre descoperirea manuscrisului și primele ediții, v. Mastandrea (ed. 2005, p. XII-XVIII). O listă a edițiilor textului latin poate fi consultată în ed. 2017, p. LV-LVI.

${ }^{3}$ Despre scopul redactării lucrării la atîtea veacuri după petrecerea evenimentelor, v. și Santini (1988, p. 212). Nu trebuie neglijată nici dimensiunea politico-socială pe care o capătă interpretarea semnelor divine. Ne întrebăm dacă nu cumva ar putea fi vorba și despre o intenție didactică (alcătuirea unui manual care să-i instruiască pe tineri asupra fenomenor supranaturale ieșite din comun, a miracolelor și influenței acestora în interpretarea evenimentelor istorice din trecut). XVII).

${ }^{4}$ V., spre exemplu, discuția asupra surselor în Moore (1904); Schmidt (1968); Santini (1988, p. 215); Trixi (2017, p. XII-

\footnotetext{
${ }^{5}$ Santini (1988, p. 215-216). Despre Annales Maximi, v., spre exemplu, Alfonsi (1973); Frier (1999).
} 
Claudia Tărnăuceanu

numit de Luterbacher (1904, p. 43) Prodigienstil. Deși exegeții au acordat importanță îndeosebi studiului limbajului specific acestui tip de literatură (e.g. Luterbacher, 1904; Rocca, 1978; Rocca, ed. 2017 , p. XXXI-LIII), numit sermo prodigialis, scriitura lui Obsequens a fost analizată și din punctul de vedere al particularităților stilistice, fiind identificate o serie de figuri (e.g. aliterație, homoioteleuton, polyptoton, chiasmus, climax), al căror uz, observă Santini (1988, p. 226), este emfatic, ușor naiv și provincial. La o lectură atentă, în scrierea lui Obsequens ne atrage atenția și un alt tip de „figură” topică, hyperbaton-ul.

\section{Precizări metodologice}

Hyperbaton-ul presupune afectarea contiguității unor unități lingvistice (legate sintactico-semantic) prin introducerea în cadrul acestora a unui cuvînt sau mai multe. Considerat și studiat multă vreme doar ca figură stilistică, ocurentă în textele literare latine (e.g. Berger, 1942, p. 325) ${ }^{6}$, în ultima vreme, hyperbatonul este analizat mai ales din punctul de vedere al rolului său pragmatic (e.g. Spevak, Powell, Pinkster).

Deși, în general, în latină, ordinea cuvintelor într-o propoziție era destul de laxă, cercetătorii moderni au observat în latina tîrzie tendința de stabilizare a topicii în cadrul grupurilor sintactice, îndeosebi al celor nominale (Herman, 2001, p. 100), prin păstrarea determinantului alături de cuvîntul-centru. Totuși, deși cu un uz mai restrîns, hiperbatul continuă să fie întîlnit și în latina tîrzie, în textele literare, dar și în alte categorii de scrieri ${ }^{7}$, în care, de cele mai multe ori, nu are rol ornamental, ci pragmatic, la fel ca în vorbirea curentă $^{8}$. Întrucît textul lui Obsequens se încadrează în categoria celor de „specialitate”, tehnice, unde accentul este pus pe concizie și claritate, este de așteptat ca folosirea hiperbatului ca ornament să fie destul de restrînsă. Analiza noastră urmărește atît uzul hyperbaton-ului ca mijloc pragmatic de punere în relief, cît și evidențierea eventualelor valențele expresive ale dislocărilor în Prodigiorum liber.

Vom numi grup nominal simplu unitatea sintactico-semnatică formată dintr-un substantiv și un determinant adjectival sau substantival în genitiv; grup nominal complex unitatea alcătuită din substantivulcentru și doi sau mai mulți determinanți; grup prepozițional simplu unitatea sintactică formată din prepoziție și numele pe care îl precede; grup prepozițional complex unitatea formată din prepoziție și grupul nominal pe care îl guvernează numele precedat; grup verbal unitatea sintactică formată dintr-un verbcentru și determinanții săi obligatorii (complemente) și facultativi (circumstanțiale). Dislocările sintactice presupun „spargerea” acestor grupuri prin interpunerea unuia sau a mai multor elemente.

În Prodigiorum liber, cele mai frecvente dislocări se produc în cadrul grupurilor nominale, care au un grad mai mare de coeziune, dar pot fi întîlnite și în cadrul grupurilor prepoziționale și verbale. Elementul dislocant este un cuvînt sau un grup de cuvinte, o particulă sau o întreagă propoziție. Cele mai frapante situații sînt, bineînțeles, cele în care disjunctorul nu aparține grupului pe care îl „sparge”, intenția fiind, de obicei, aceea de a obține efecte stilistice 9 .

\section{Hyperbata în Prodigiorum liber}

O parte dintre dislocările întîlnite în Prodigiorum liber este impusă de șablonul specific acestor scrieri, în care, de regulă, secvențele încep prin a menționa timpul și locul unde se constată apariția fenomenului ieșit din comun. Dacă anul este anunțat printr-o construcție în ablativ, precedînd întreaga secvență în care sînt prezentate evenimentele petrecute pe parcursul anului respectiv, locul este specificat în deschiderea fiecărui segment care conține un nou prodigiu. Inevitabil, aceste circumstanțiale sînt despărțite de verbul regent printr-unul sau mai multe cuvinte (e.g. In Gallia tres soles et tres lune visæ. ${ }^{10}$ - 32 - „In Gallia,

\footnotetext{
${ }^{6}$ V. și Marouzeau (1922, p. 99-118; 1953, p. 10-12).

${ }^{7}$ Spevak (2012, p. 255-256). Cf. Herman (1985, p. 333-334).

${ }^{8}$ Includem în categoria hiperbatului și ceea ce unii cercetători numesc „inversiune”, adică schimbarea ordinii cuvintelor în interiorul aceluiași grup sintactic (cf. Panhuis, 1982, p. 73, n. 8). Despre ocurența dislocărilor sintactice în cinci texte de facturi diferite din latina tîrzie, v. Spevak (2012).

${ }^{9}$ Observăm o creștere a numărului de dislocări spre sfîrșitul opusculului, unde sînt prezentate evenimentele din perioada republicii tîrzii, pentru care sursele îi oferiseră lui Obsequens mai multe informații.

${ }^{10}$ Am selectat exemplele din ediția 2017 (confruntînd textul cu cel al ediției 2005).
} 
au fost văzuți trei sori și trei luni. ${ }^{11}$ ", unde circumstanțialul in Gallia este despărțit de verbul regent vise, eliptic de auxiliarul esse, prin două grupuri nominale simple, care alcătuiesc subiectul multiplu). Astfel de dislocări își găsesc utilitatea practică în a plasa fără echivoc evenimentele în spaţiu și timp ${ }^{12}$.

O altă serie de dislocări, impusă de caracterul „tehnic” al textului, este cea din cadrul formulelor repetitive. În exemplul: Fulmine pleraque decussa ${ }^{13}$ (15, 17, 24, 47, 49, 52 - „multe altele au fost doborîte de fulger”), formulă recurentă în text ${ }^{14}$, plasarea lui fulmine în poziție inițială și despărțirea sa de verb (eliptic de auxiliarul esse) prin subiectul pleraque ${ }^{15}$ face ca accentul să cadă asupra sa, ca forță care produce dezastrul ${ }^{16}$. Secvența fulmine pleraque devine, de altfel, stereotipă în text, putînd fi urmată și de alte verbe, în funcție de cît de puternică este acțiunea fulgerului și de rezultatul acesteia: fulmine pleraque icta (20, 53, 69); Fulmine pleraque deiecta $(25,29)$; fulmine pleraque tacta $(36,46,68)$. Gradul de coeziune al acestei secvențe (în care fulmine și pleraque nu sînt totuși legate sintactic) este atît de mare, încît introducerea altor elemente în cadrul ei pare a produce o dislocare: Fulmine Rome et circa pleraque tacta (36) („De fulger, la Roma și în împrejurimi, au fost atinse multe altele").

În cadrul grupului prepozițional complex, dislocarea, opțională și fără a reprezenta un procedeu de ornamentare stilistică, obişnuită și în latina clasică, se face prin interpunerea între prepoziție și substantiv a unui element în genitiv, aparținînd sintactic grupului nominal care are ca centru substantivul precedat de prepoziție: per hostium classem adnatavit (60a $)^{17}$ („a înotat prin flota dușmanilor”); supra deorum simulacra (47) („deasupra statuilor zeilor”); in agrorum divisione (33) („în privința împărțirii ogoarelor”). Pronumele anaforic is, în genitiv plural, după model clasic, apare o singură dată în această poziție ${ }^{18}:$ in eorum finibus $(21)^{19}$ (,în hotarele acestora”).

O situație aparte o reprezintă construcția vervecum de grege pars (14) („o parte dintr-o turmă de batali”), unde situarea genitivului explicativ vervecum înaintea prepoziției este un ornament stilistic. Topica, insolită la Obsequens (cf. gregem vervecum - 52) ${ }^{20}$, surprinde și atrage totodată atenția atît asupra victimelor fenomenului, cît și asupra ideii de partiție, sugerată de folosirea ablativului cu de în locul genitivului partitiv.

Întregul grup nominal, cu centru pars, din care fac parte și celelalte trei componente, este, de altfel, disjunctorul unui grup verbal, fulgure vervecum de grege pars exanimata (14) („o parte dintr-o turmă de

\footnotetext{
${ }^{11}$ Traducerea ne aparţine. Am încercat, pe cît posibil, să oferim echivalări cît mai apropiate de text.

${ }^{12} \mathrm{Nu}$ sînt totuși puține situațiile în care cuvîntul cu funcția semantică de Locativ nu se află în poziția inițială, aceasta fiind cedată altor elemente. E.g. Medorum gens in Macedonia provinciam cruente vastavit (53) („Neamul mezilor, în Macedonia, a devastat sîngeros provincia”), accentul cade asupra etnonimului aflat pe prima poziție, atacul unei populații orientale fiind anticipat de o serie de prodigii expusă anterior și de eșecul ritualului expiatoriu; in Macedonia (cu funcția semantică de Locativ) aduce o informație suplimentară.

${ }^{13}$ Cf. Tit. Liv., 25, 7: non icte modo fulminibus sed etiam decusse.

${ }^{14}$ Expresia poate fi însoțită și de alte elemente, menite să precizeze locul unde se petrece fenomenul: Fulmine pleraque decussa in Palatio (14).

${ }^{15}$ Aici cu rolul pragmatic de temă (element despre care vorbitorul alege să ofere informații receptorului); v. Pinkster (2021, p. 830, 951), care folosește termenul de „Topic”.

${ }^{16}$ Rolul pragmatic este cel pe care Pinkster (2021, p. 839, 951) îl numește „Focus” (oferă despre subiect informații importante pentru adresant). Despre singularul fulmine, văzut ca rezultat al unei singure acțiuni, a unui singur zeu, v. Gusso (2005, p. 46).

${ }^{17}$ Termenul hostium are rolul de a relua, de fapt, o informație deja cunoscută din sintagma ocurentă în propoziția anterioară, turres hostium, unde genitivul este poziționat după numele determinat. Cf. Spevak (2010, p. 168), care observă că, dacă nu este anaforic, în latina clasică, genitivul este plasat după regent.

${ }^{18} \mathrm{La}$ Obsequens, valoare anaforică, asemănătoare lui is, poate avea pronumele de întărire ipse: in ipsius conspectu (69) (,sub privirea acestuia”); flamma ex ipsius ore nata (14) („o flacără ivită din botul acestuia”). În acest ultim exemplu, întregul grup prepozițional guvernat de ex produce, la rîndu-i, separarea substantivului flamma de nata.

${ }^{19}$ E.g. Cæs, B.G., I, 1; I, 31. Despre această ordine în cadrul grupului prepozițional (poziționarea genitivului posesiv în stînga substantivului-centru), v., spre exemplu, Devine \& Stephens (2006, p. 361).

${ }^{20}$ Autorul preferă ordinea obişnuită, care presupune situarea genitivului explicativ după substantivul grex: grex ovium (28, 31); grex luporum (33); grex piscium (68).
} 
batali a fost omorîtă de fulger”), cu centrul exanimanta (verb predicat eliptic de auxiliarul esse). Apariția lui fulgure, avînd în această structură același rol emfatic pe care îl are fulmine în cele prezentate mai sus, un hapax legomenon la Obsequens ${ }^{21}$, poate susține interpretarea secvenței ca avînd un grad sporit de expresivitate.

Există un singur caz în care grupul prepozițional este dislocat de encliticul -que, care face corp comun cu prepoziția circa ${ }^{22}$ : Soles tres fulserunt, circaque solem imum corona spicea similis in orbem emicuit (68) („Trei sori au strălucit și în jurul celui mai de jos a scăpărat o coroană ca de spice, în formă de disc”).

În cadrul grupurilor nominale complexe, în mod obișnuit, determinantul în genitiv este poziționat după sau înainte de sintagma alcătuită din substantiv și adjectiv ${ }^{23}$.

Textul opusculului oferă însă și exemple de hyperbata opționale, în care un cuvînt în genitiv, legat sintactic de substantivul-centru, este disjunctorul sintagmei ${ }^{24}:$ Padus... ingentem viperarum vim reliquit (68) („Padul... a lăsat în urmă o uriașă mulțime de vipere”) - rolul pragmatic al întregului grup nominal este acela de „Focus”; aliterația, viperarum vim, marchează suplimentar dimensiunile fenomenului.

$\mathrm{O}$ astfel de încadrare a genitivului poate indica unitatea construcției, stabilindu-i limitele (Spevak, 2012, p. 261), dar poate avea și rol emfatic: simulacrum Martis ligneum (42) (literal „statuia lui Marte de lemn”), unde numele zeului este relevant pentru interpretarea prodigiului ${ }^{25}$.

În fragmentul: ingens signorum sonus armorumque horrendo clamore auditus (57) (literal: „un puternic de trompete sunet și de arme cu un zgomot înspăimîntător s-a auzit”), unde topica așteptată ar fi ingens sonus signorum armorumque, pare a exista un „hiperbat intern dublu”, căci, în cadrul grupului nominal, genitivul signorum desparte adjectivul de numele determinat, iar numele-centru, la rîndu-i, desparte cele două genitive aflate într-un strîns raport de coordonare prin encliticul -que. Nu ar fi exclusă aici nici posibilitatea unui lapsus calami, în locul unui nominativ clamor, de care să depindă armorum, fiind folosit ablativul.

În fragmentul filia eius virgo (37) („fiica acestuia, fecioară”), pronumele desparte apoziția de substantivul determinat, iar rolul pragmatic al acestei apoziții este acela de apendice $(\text { „Tail” })^{26}$, care aduce o lămurire suplimentară.

Dislocările din cadrul grupurilor nominale pot fi produse și de elemente nelegate sintactic de acestea ${ }^{27}$. Cercetătorii moderni au identificat mai multe tipuri de disjunctori ${ }^{28}$ : a. particule enclitice, sudate de termenul anterior $(-q u e,-v e,-n e)$; conectori postpozitivi (autem, vero, enim ${ }^{29}$, care, de obicei, ocupă locul secund în enunț); particule și adverbe postpozitive focalizante (precum quidem, quoque, etiam, vel, modo, solum ${ }^{30}$ ); b. conjuncții subordonatoare (e.g. cum, quia, postquam, si) ${ }^{31}$, care, în mod normal, sînt poziționate în deschiderea subordonatei; c. nume, verbe sau grupuri nominale sau verbale; d. propoziții.

a. Dislocarea produsă de elemente din primele trei categorii este slab reprezentată la Obseques. Dintre enclitice, este folosită doar conjuncția coordonatoare -que, care are rolul său obișnuit de a lega strîns două cuvinte de același fel și cu același rol sintactic (e.g. hominum boumque cadavera - $10-$ „cadavrele oamenilor și ale vitelor”). Conjuncția -que, postpusă primului element (care poate fi atît

\footnotetext{
${ }^{21}$ V. și Trixi (ed. 2017, n. 76, p. 73).

${ }^{22}$ Combinația prepozițiilor bisilabice cu acest enclitic era rară și în latina clasică (Spevak, 2010, p. 18, n. 12).

${ }^{23}$ V. și Spevak (2012, p. 260), care constată că astfel de disclocări apar și la autorii perioadei tîrzii.

${ }^{24}$ Spevak (2010, p. 272-275) numește acest tip de dislocare „internal hyperbaton”.

${ }^{25}$ Răsturnarea statuii unei divinități a războiului, de la care romanii își revendicau originea, nu putea aduce decît prevestiri sumbre în privința soartei trupelor militare (despre care aflăm din propoziția următoare că au fost înfrînte de lusitani).

${ }^{26}$ V. Cabrillana (2019, p. 227); Pinkster (2021, p. 857).

${ }^{27} \mathrm{O}$ serie de cercetători consideră că doar într-o astfel de situație este vorba de o dislocare reală, întrucît coeziunea grupului este „spartă”, iar coerența acesteia se pierde.

${ }^{28}$ Spevak (2012, p. 254); Pinkster (2021, p. 1099).

${ }^{29}$ Cf. Spevak (2010, p. 16).

${ }^{30}$ Spevak (2010, p. 20). Cf. partea dedicată de Devine \& Stephens (2006, p. 249-275) lianților de focalizare.

${ }^{31}$ Pinkster (2021, p. 1099); Spevak (2010, p. 14).
} 
substantivul-centru, cît și determinantul acestuia), „separă” sintagma nominală, dar are acelaşi rol de a evidenția legătura cu secvența anterioară: Procellosa tempestate tecta diruta stragesque agrorum facta. (14) („Acoperișurile au fost năruite de o furtună năprasnică și s-a produs distrugerea ogoarelor”); ...sol noctu visus, eiusque lux aliquamdiu fuit visa. (27) („,...soarele a fost văzut noaptea și lumina lui a fost vizibilă multă vreme”); Puer aruspicum iussu crematus cinisque eius in mare deiectus. (25) („Un copil <diform> a fost ars din porunca haruspicilor și cenușa lui a fost aruncată în mare") ${ }^{32}$.

Conectorul autem este singurul din a doua categorie de elemente dislocante care apare în Prodigiorum liber (doar o singură dată: Abrogaverunt autem hi - 70 - „i-au destituit însă aceștia”), dar, în secvența deschisă emfatic de verbul predicat, ocupă locul său obișnuit în enunț (a doua poziție).

Dintre elementele focalizante, doar quoque are rolul de disjunctor al unui grup nominal ${ }^{33}$ : Ilio a C. Fimbria incenso, cum edes quoque Minerve deflagrasset, inter ruinas simulacrum antiquissimum inviolatum stetit... (56b) („Cînd a fost incendiat Ilionul de către C. Fimbria, după ce chiar și templul Minervei a ars, a rămas în picioare, între ruine, neatinsă, o statuie foarte veche...") - exemplu în care quoque dislocă cele două componente ale sintagmei ades Minerva, pe care le scoate în relief (semnificația prodigiului fiind reconstruirea cetății, despre care se pomenște în continuare).

b. Frecvente în textul lui Obsequens sînt dislocările provocate de conjuncția subordonatoare cum.

De obicei, termenul pe care conjuncția îl desparte de restul subordonatei este cel accentuat (prevestirea este direct legată de acesta): e.g. Pireum Sylla cum oppugnaret diuturno labore, unus miles eius aggerem ferens exanimatus fulmine. (56b) („Pe cind Sulla ataca Piræus cu eforturi îndelungate, un soldat al acestuia, care ducea materiale pentru întărituri, a fost omorît de fulger") ${ }^{34}$; Cesar cum in campum Martium exercitum deduceret, sex vultures apparuerunt. (69) („Cînd Cæasar /Octavianus n.n./ a dus armata pe cîmpul lui Marte, au apărut șase vulturi”) ${ }^{35}$. In exemplul P. Elvius eques Romanus a ludis Romanis cum in Apuliam reverteretur, in agro Stellati flita eius (....) fulmine icta (37), întregul grup al subiectului și un component opțional din catena predicatului sînt despărțite de restul propoziției prin cum.

c. Dislocările produse de nume, grupuri nominale sau grupuri prepoziţionale nu sînt numeroase.

Disjunctorul poate fi un grup nominal în componența căruia intră un numeral: stella hora undecima crinita sub septemtrionis sidere exorta, convertit omnium oculos (68) („o cometă ivită la ora a unsprezecea sub regiunea nordică a cerului a întors <către ea> privirile tuturor”) - sensul de „cometă” îl are sintagma stella crinita, iar informația legată de momentul apariției cometei, inserată între cele două componente ale sintagmei, este esențială ${ }^{36}$; Stella per dies septem insignis arsit (68) („o stea fără seamăn s-a aprins timp de șapte zile”) - epitetul insignis, cu rol ornamental, este separat de numele determinat de o sintagmă prepozițională complexă $\breve{a ̆}^{37}$.

Inserarea sintagmei uno tempore, cu valoare adverbială în exemplul Tres uno tempore virgines Vestales nobilissime (37) („În același timp trei fecioare vestale de cel mai nobil neam”) desprinde numeralul tres de restul grupului nominal, accentuîndu-l.

Uneori, hiperbatul, folosit ca ornament, este însoțit și de o altă figură stilistică (e.g. aliterația: os flamma ferrugineum ostendit - 52) („flacăra a arătat o gură de culoare ruginie”).

\footnotetext{
${ }^{32}$ Dacă cele două exemple anterioare conțineau prodigia, în acesta este vorba despre procuratio (ceremonie religioasă de expiere), presupunînd obligatoriu, în această situație, desfăşurarea celor două acțiuni (arderea și aruncarea cenușii în mare), a căror legătură este evidențiată de folosirea lui -que.

${ }^{33}$ Rolul său aici nu este acela de simplu aditiv, într-un context descriptiv (adăugînd încă un edificiu unei serii de mai multe clădiri arse), ci este mai curînd argumentativ. V. și Orlandini (2001, p. 211-212).

${ }^{34}$ Cum desparte atît complementul Pireum, cît și subiectul Sylla de restul propoziției din care fac parte.

${ }^{35}$ Prodigiul a servit propagandei lui Octavianus (prin asocierea cu Romulus). V. și Gusso (ed. 2005, n. 12, p. 249).

${ }^{36}$ Fenomenul, petrecut în 44 a.C., a jucat un rol important în apoteoza lui Cæsar, cometa fiind interpretată ca sufletul acestuia primit în cer (Suet., Ces., 1, 88); astrul a primit denumirea de sidus Iulius (Hor., Carm., 1.12.47) și a fost reprezentat pe monedele din epoca augustană. Desigur, interpretarea fenomenului a avut scop propagandistic.

${ }^{37}$ Importanța prodigiului pare a fi subliniată și de numărul impar.
} 
Dislocările provocate de verbe sau grupuri verbale (hiperbatul verbal) ${ }^{38}$ au, de asemenea, valoare ornamentală.

Aceste dislocări nu sint motivate pragmatic, ci utilizate din rațiuni stilistice, fiind prezente îndeosebi

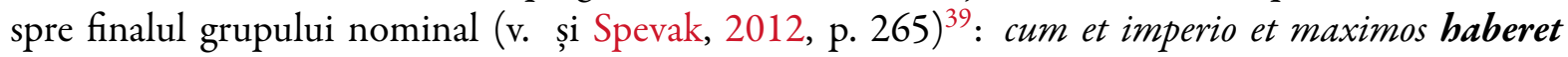
exercitus (56a) („deoarece avea atît puterea supremă, cît și o foarte mare armată”); ...odore intolerabili <et> mortifero vapore gravem pestilentiam fecerunt pecorum hominumque (30) („printr-o miasmă insuportabilă și o exalație aducătoare de moarte au provocat o boală gravă a turmelor și oamenilor”) - unde verbul-predicat „sparge” coeziunea grupului nominal, despărțind genitivele de substantivul determinat.

În Prodigiorum liber, astfel de dislocări apar adesea în cadrul unor sintagme care exprimă tipul prevestirii, evidențiindu-le: ...fruges et tempestates portendit bonas $(47)$ (,.... prevestit recolte și vremuri bune”); civiles portendere discordias (48) („au prevestit neînțelegeri civile”); Proditum est memoria Tiberium Gracchum, quo die periit, tristia neglexisse omina (27a) („S-a transmis că Tiberius Gracchus, în ziua în care a murit, a neglijat prevestirile de rău").

Rareori, componentele dislocate ale unei sintagme nominale se află la o distanță mare una de cealaltă ${ }^{40}$, intenția stilistică fiind augmentarea efectului produs de fenomenul supranatural: In \&de Larum flamma a fastigio ad summum columen penetravit innoxia. (41) („În templul Larilor, o flacără care nu arde a pătruns de la fronton pînă în vîrful acoperișului”) - sintagma flamma... innoxia este separată de grupul verbal cu centru penetravit; Mons Ætna maioribus solito arsit ignibus. (26) („Muntele Ætna a ars cu un foc mai puternic decît de obicei”).

În cadrul grupului nominal simplu caput iocineris („vîrful ficatului”), format din substantiv și determinantul său în genitiv, expresie care aparține limbajului tehnic al artei divinatorii, disjuncția produsă de verb are menirea de a marca, în context, importanța unor exta tristia („măruntaie rău prevestitoare”): Rutilius Lupus spretis religionibus cum in extis caput non invenisset iocineris, amisso exercitu in proelio occisus. $(55)^{41}$ („Rutilius Lupus, deoarece disprețuia credințele religioase, după ce nu a găsit în măruntaie vîrful ficatului, pierzîndu-și armata, a fost ucis în luptă”).

În cadrul predicatului nominal, situarea copulei între numele predicativ şi subiect poate fi considerată tot o dislocare: adversa fuerunt fulmina (65a) („potrivnice i-au fost fulgerele”); Ipsi Cesari ...generosa fuit ad resistendum constantia. (68) („Cæsar /Octavianus n.n./ însuși... a dovedit o mare stăruință de a rezista"). Valoarea expresivă a figurii poate fi sporită de adăugarea unui alt element: Tanta fuit Lunensibus pestilentia utiacentibus in publicum passim cadaveribus quifunerarent defuerint (22) („Atît de mare a fost pentru cei din Luna molima, încît, deși cadavrele zăceau peste tot în locuri publice, lipseau cei care să le înmormînteze"). Accentul cade asupra adjectivului intensiv, care ocupă emfatic poziția iniţială.

d. Hiperbatul produs de o întreagă propoziție este, de asemenea, folosit ca ornament stilistic: vulturum et aliarum alitum quibus strages cadaverum pabulo est ingens vis exercitum advolavit. (70) („O năvală uriaşă de vulturi şi alte zburătoare cărora le este hrană mormanul de cadavre a zburat către armată”) - componentele grupului nominal vulturum et aliarum alitum... vis sînt despărțite de o întreagă subordonată relativă.

În cadrul grupului verbal, disjuncția este dată de includerea unuia sau a mai multor elemente alogene în

\footnotetext{
${ }^{38}$ Adams (1971).

${ }^{39}$ Spevak (2012, p. 265) este de părere că, în sintagmele nominale, scopul lor stilistic este acela de a marca limitele acesteia.

${ }^{40}$ Pentru a denumi acest tip de dislocare, Powell (2010, p. 174-176) folosește sintagma „long-range hyperbaton”.

${ }^{41}$ Expresia, fără dislocare, are mai multe ocurențe, dar în contexte unde este anunțat sec prodigiul, fără a-i fi consemnate urmările: Catone consule immolante exta tabuerunt, caput iocineris inventum non est (35); Apud adem Apollinis decemviris immolantibus caput iocineris non fuit, sacrificantibus anguis ad aram inventus. (47); Herennio consuli bis immolanti caput iocineris defuit. (52).
} 
catena predicatului.

Lucum Furiarum cum Mithridates succenderet, risus exauditus ingens sine auctore (56) („Cînd Mithridates a incendiat dumbrava sacră a Furiilor, s-a auzit un rîs puternic fără a se ști de la cine”) - coeziunea din cadrul grupului verbal cu centru succenderet și determinant obligatoriu lucum (cu funcția sintactică de complement direct) este spartă de interpunerea conjuncției subordonatoare cum și a subiectului Mithridates.

...bovem flamma ex ipsius ore nata non lasit (14) („pe un bou o flacără ivită din botul acestuia nu l-a rănit”) - bovem, complementul obligatoriu al verbului-predicat lesit, cu funcția pragmatică de temă, este poziționat în deschiderea secvenței, cele două elemente ale acestui grup verbal încadrînd grupul nominal cu centru flamma.

Dislocarea poate afecta și grupul verbal care conține un component adverbial: quod immunde sua templa feedarentur (55) („deoarece templele sale au fost pîngărite în mod nerușinat”).

\section{Concluzii}

În urma analizei noastre, am observat că, în pofida caracterului „tehnic” al scrierii, hyperbaton-ul este prezent în Prodigiorum liber, fiind însă rareori utilizat ca ornament stilistic. Ariditatea textului, încorsetarea în anumite canoane care obligă la prezentarea fenomenelor într-o anumită ordine (întîi prodigiul, apoi rezultatul și interpretarea acestuia) fac ca rolul hyperbaton-ului să fie unul preponderent pragmatic.

\section{Bibliografie}

\section{A. Editiii}

Ossequente (2005). Prodigi, Introduzione e testo di Paolo Mastandrea; traduzione e note di Massimo Gusso, Mondadori, Roma.

Ossequente (2017). Il libro dei Prodigi, Saggio introduttivo, nuova traduzione et note a cura di Mariella Trixi, con un Saggio di Silvana Rocca, testo latino a fronte, Rusconi Libri, Milano.

\section{B. Studii și articole}

Adams, J.N. (1971). A Type of Hyperbaton In Latin Prose, în „Proceedings of the Cambridge Philological Society”, 17, p. 1-16. Alfonsi, L. (1973). La prosa e lo stile degli Annales Maximi, în „Studii Clasice”, 15, p. 51-55.

Berger Ernst. (1942). Stylistique latine, Klincksieck, Paris.

Cabrillana, C. (2019). La dislocation à droite en latin : analyse d'une structure spécifique, în Fatello, F., Taillade, M., Gallego, J. \& Gibert, G. (eds), Nemo par eloquentia: Mélanges de linguistique ancienne en hommage à Colette Bodelot, Presses Universitaires Blaise Pascal, Clermont-Ferrand.

Devine, A.M. \& Stephens, L.D. (2006). Latin Word Order: Structured Meaning and Information, Oxford University Press, Oxford, Crossref.

Frier, B. W. (1999). Libri Annales Pontificum Maximorum. The Origins of the Annalistic Tradition, The University of Michigan Press, Ann Arbor.

Gusso, M. (2005). Il prodigio del fulmine nell'antichità, Quaderno no 8, p. 41-62.

Herman, J. (1985), La disparition de la déclinaison latine et l'évolution du syntagme nominal, în Kiss, S. (ed.), Du latin aux langues romanes : études de linguistique historique, Tübingen, p. 326-337.

Herman, J. (2001). El latín vulgar, traducción, índice y bibliografía de Carmen Arias Abellán, Editorial Ariel, S.A., Barcelona. Luterbacher, F. (1904). Der Prodigienglaube und Prodigienstil der Römer. Eine historisch-philologische Abhandlung, Burgdorf.

Marouzeau, J. (1922). Lordre des mots dans la phrase latine, vol. I. Les groupes nominaux, Les Belles Lettres, Paris.

Marouzeau, J. (1953). Lordre des mots en latin, volume complémentaire avec exercices d'application et bibliographie, Les Belles Lettres, Paris.

Moore, C. (1904). The Oxyrhynchus Epitome in Relation to Obsequens and Cassiodorus, în „The American Journal of Philology”, 25, p. 241-255, Crossref.

Orlandini, A. (2001). Grammaire fondamentale du latin. Négation et argumentation en latin, vol. VIII (Bibliothèque d'études classiques), Peeters, Leuven.

Panhuis, D. G.J. (1982). The Communicative Perspective in the Sentence. A Study of Latin Word Order, John Benjamins Publishing Company, Amsterdam/Philadelphia, Crossref.

Picone, G. (1974). Il problema della datazione del Liber prodigiorum di Giulio Ossequente, în „Pan”, 2, p. 71-77. 
Pinkster, H. (2021). The Oxford Latin Syntax, vol. 2. The Complex Sentence and Discourse, Oxford University Press, Oxford, Crossref.

Powell, J.F. G. (2010). Hyperbaton and Register in Cicero, în Dickey, E. \& Chahoud, A. (eds), Colloquial and Literary Latin, Cambridge University Press, p. 163-185.

Rocca, S. (1978). Iulii Obsequentis Lexicon, Genova.

Santini, C. (1988). Letteratura prodigiale e sermo prodigialis in Giluio Ossequente, în „Philologus”, 32, p. 210-226.

Schmidt, P. (1968), Julius Obsequens und das Problem der Livius-Epitome. Ein Beitrag zur Geschichte der lateinischen Prodigienliteratur, Akad. der Wiss. in Mainz 5, p. 155-42.

Spevak, O. (2012). La disjonction en latin tardif, in Latin vulgaire - latin tardif IX. Actes du IXe colloque international sur le latin vulgaire et tardif, Lyon 2-6 septembre 2009, Maison de l'Orient et de la Méditerranée Jean Pouilloux, Lyon, p. $253-269$. (Collection de la Maison de l'Orient méditerranéen ancien. Série philologique, 49).

Spevak, O. (2010). Constituent order in Classical latin prose, în „Studies in Language Companion Series”, 117, John Benjamins Publishing Company, Amsterdam, Crossref. 